\title{
Sowing windows influence on growing degree days (GDD) and heliothermal units (HTU) in soybean
}

\section{S.R. PATIL, N.R. SATPUTE AND M.G. JADHAV}

Article Chronicle : Received: 17.10.2013;

Revised :

19.03.2015;

Accepted :

10.04.2015
ABSTRACT : The GDD was higher in $\mathrm{D}_{2}(\mathrm{MW}-28)$ i.e. $164.2^{\circ} \mathrm{C}$ followed by $\mathrm{D}_{3}(\mathrm{MW}-29)$ than rest of the treatments, whereas, the lowest GDD was recorded in $\mathrm{D}_{4}(\mathrm{MW}-30)$ i.e. $150.8^{\circ} \mathrm{C}$. Mean heat load was reported same in four varieties $\mathrm{V}_{2}$ (MAUS-71), $\mathrm{V}_{3}$ (MAUS-81), $\mathrm{V}_{4}$ (MAUS-158) and $\mathrm{V}_{6}$ (JS-9305) i.e. $160.9^{\circ} \mathrm{C}$, it may be due to same crop duration in these four varieties. Whereas, $\mathrm{V}_{1}$ (MAUS-47) variety indicated less heat load than other varieties i.e. $147.3^{\circ} \mathrm{C}$, which may be due to small crop duration from emergence to maturity of such varieties. Helio thermal units directly or indirectly affected the grain yield of soybean by delaying flowering and pod formation. The requirement of HTU was higher (925.0) in $\mathrm{D}_{2}$ (MW-28), whereas, HTU requirement was lower (825.8) in $\mathrm{D}_{1}$ (MW-27) treatment. The mean helio thermal units was reported same in four varieties $\mathrm{V}_{2}$ (MAUS-71), $\mathrm{V}_{3}$ (MAUS-81), $\mathrm{V}_{4}$ (MAUS-158) and $\mathrm{V}_{6}$ (JS-93-05) i.e. $915.0^{\circ} \mathrm{C}$. It may be due to the same crop duration in above four varieties. Whereas, lowest heliothermal unit was recorded in $\mathrm{V}_{1}$ (MAUS-47) i.e. $823.5^{\circ} \mathrm{C}$.

How to CITE THIS ARTICLE : Patil, S.R., Satpute, N.R. and Jadhav, M.G. (2015). Sowing windows influence on growing degree days (GDD) and heliothermal units (HTU) in soybean. Asian J. Environ. Sci., 10(1): 13-19.

Key Words :

Sowing windows, Growing degree day, Heliothermal soybean 